\title{
Load Bearing and Deformation Capacity of Fire Resistance Steel Tubular Columns at Elevated Temperature
}

\author{
H. UESUGI, T. SOMEYA and H. SAITOH \\ Department of Architectural Engineering \\ Faculty of Engineering, Chiba University \\ 1-33, Yayoicho, Chiba, 260, Japan

\section{S. KUBOTA and S. SAKUMOTO} \\ Construction \& Architectural Materials \\ Development \& Engineering Service DIV. \\ Nippon Steel Corporation \\ Chiyoda-ku, Tokyou, 100, JAPAN
}

ABSTRACT

The design method of building structures has been trending from allowable stress design method to ultimate state design method. The ultimate state design method is based on the assumption that load bearing and deformation capacity of plastic hinges are ensured sufficiently.

Using the ultimate state design method in fire engineering design, it is necessary to investigate load bearing and deformation capacity at elevated temperature. In this study, the load bearing and deformation capacity of tubular columns made from fire resistance steel are shown, which are obtained experimentally under pure compression and bending compression at elevated temperature .

KEYWORDS: Thermal stress, thermal deformation, steel structure, local buckling, plastic hinge, structural stability, lateral deflection, load bearing

\section{INTRODUCTION}

In Japan, the required fire endurance time of building elements is prescribed to be from 1 to 3 hours classified dependent on floor number from the highest floor according to Building Standard Act $/ 1$. The fire resistance of the members which constitute fire compartment are determined based on the standard fire resistance test $/ 2 /$. On the other hand, rational fire engineering design methods have been developed based on fire behavior of fire compartment and thermal stress and deformation analys is of building structure $/ 3 /$. In this design method fire endurance of a building is estimated not only based on the behavior of the single structural members but also on the behavior of the complete structural frame. Therefore, it can be possible to recognize high grade fire resistance of buildings which could not be achieved by single member. Plastic deformation capacity of steel structural frame is expected in the new fire engineering design method and the development of the high grade fire resistance steel has been promoted.

For predicting behavior of building structure exposed to fire, many things are necessary to be verified. One of them is load bearing and deformation capacity of structural members as part of the complete structure at elevated temperature. The purpose of the present experimental study is to obtain the fundamental data about load bearing and deformation capacity of the fire 
resistance steel tubular columns with some thickness ratio under bending compression and pure compression at elevated temperature. The bending compression test means to examine the bending deformation capacity of outer column with local buckling. The pure compression test means also to examine the load bearing capacity of inner column with local buckling.

\section{BENDING COMPRESSION TEST}

Plan of bending comprssion test

It is considered that the factors which influence load bearing and deformation capacity of tubular steel columns are mechanical properties of steel, sectional geometry of members and stress conditions in members at elevated temperature.

In Japan, high rise buildings are usually designed against seismic load. Axial forces produced in columns of buildings are $15 \%$ of allowable axial force on an average at service time/4/. The grades of structural steel almost used are SM50 and width-thickness ratio of plate which constitutes tubular column is between about 20 and 30 . Range of temperature is assumed to be from room temperature to $650^{\circ} \mathrm{C}$.

According to above discussion, parameters of the experiments are set as follows.

a) Steel grade : SH490

b) Test temperature : R.T., $400^{\circ} \mathrm{C}, 500^{\circ} \mathrm{C}, 600{ }^{\circ} \mathrm{C}, 650^{\circ} \mathrm{C}$

c) Width-thickness ratio b/t : $20,25,30$

d) Constant axial load ratio: $15 \%, 30 \%$

Based on these parameters shown in Table 1, tests were carried out on 27 specimens.

Table 1 Parameters of Bending Compression Test

\begin{tabular}{|c|c|c|c|c|c|c|c|c|}
\hline \multirow{2}{*}{ Spec imen } & \multirow{2}{*}{$d / t$} & \multirow{2}{*}{$\mathbf{n}$} & \multicolumn{5}{|c|}{ Testing Temperature ( $\mathrm{C}$ ) } & \multirow{2}{*}{$\begin{array}{l}\text { Number } \\
\text { of } \\
\text { Specimen }\end{array}$} \\
\hline & & & R.T. & 400 & 500 & 600 & 650 & \\
\hline \multirow{2}{*}{$\square-135 \times 135 \times 4.5$} & \multirow{2}{*}{30} & 0.15 & 0 & 0 & - & 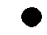 & & \multirow{2}{*}{9} \\
\hline & & 0.30 & 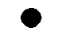 & - & - & - & 0 & \\
\hline \multirow{2}{*}{$\square-150 \times 150 \times 6$} & \multirow{2}{*}{25} & 0.15 & - & - & 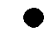 & - & & \multirow{2}{*}{9} \\
\hline & & 0.30 & 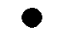 & - & & 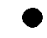 & - & \\
\hline \multirow{2}{*}{$\square-120 \times 120 \times 6$} & \multirow{2}{*}{20} & 0.15 & 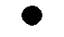 & - & 0 & - & & \multirow{2}{*}{9} \\
\hline & & 0.30 & 0 & & & 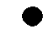 & 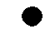 & \\
\hline
\end{tabular}

$\mathrm{d} / \mathrm{t}$ : width thickness ratio $\mathrm{n}$ : axial ratio

Specimens of bending compression test

The specimens are made from steel plates by welding. The shapes and geometries of specimens are shown in Fig. 1. Geometrical and mechanical properties of the steel specimens tested are shown in Table 2. The length of

Table 2 Section Factors and Mechanical Properties of Specimens

\begin{tabular}{|l|c|c|c|c|c|c|c|c|c|}
\hline Specimen & $\mathrm{d} / \mathrm{t}$ & $\begin{array}{c}\mathrm{A} \\
\mathrm{cm}^{2}\end{array}$ & $\begin{array}{c}\mathrm{I} \\
\mathrm{cm}^{4}\end{array}$ & $\begin{array}{c}\mathrm{i} \\
\mathrm{cm}\end{array}$ & $\begin{array}{c}\mathrm{Z} \\
\mathrm{cm}^{3}\end{array}$ & $\begin{array}{c}\mathrm{Zp} \\
\mathrm{cm}^{3}\end{array}$ & $\begin{array}{c}\sigma \mathrm{y} \\
\mathrm{t} / \mathrm{cm}^{2}\end{array}$ & $\begin{array}{l}\mathrm{My} \\
\mathrm{t} \cdot \mathrm{cm}\end{array}$ & $\begin{array}{l}\mathrm{Mp} \\
\mathrm{t} \cdot \mathrm{cm}\end{array}$ \\
\hline $\mathrm{\square}-135^{2} \times 4.5$ & 30 & 24.5 & 667.5 & 5.33 & 98.9 & 115.0 & 4.07 & 402.5 & 468.1 \\
\hline$\square-150^{2} \times 6$ & 25 & 34.6 & 1196.5 & 5.88 & 159.6 & 186.7 & 4.07 & 649.3 & 760.0 \\
\hline$\square-120^{2} \times 6$ & 20 & 27.4 & 594.3 & 4.66 & 99.6 & 117.1 & 4.07 & 403.1 & 476.1 \\
\hline
\end{tabular}


specimens is $1,200 \mathrm{~mm}$ and the range of measuring portion where temperature distribution is rather uniform is $600 \mathrm{~mm}$ length between a diaphragm and measuring point $B$ in a specimen as shown in Fig. 1.

The stress-strain curves of the fire resistance steel at elevated temperature are shown in Fig. 2.

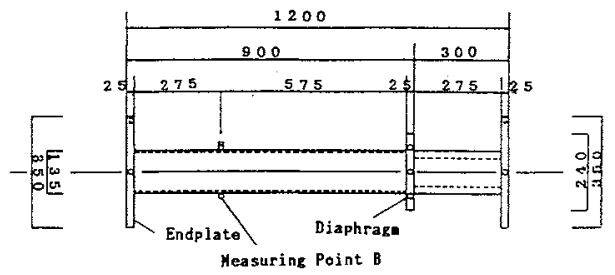

Stress-Strain Equation $\varepsilon=\frac{\sigma}{\overline{\mathrm{E}}_{\mathrm{T}}}+\left(\frac{\sigma}{\sigma \mathrm{\sigma}}\right)^{\mathbf{k}}$

Pig. 1 Shape and Geometry of Specimens

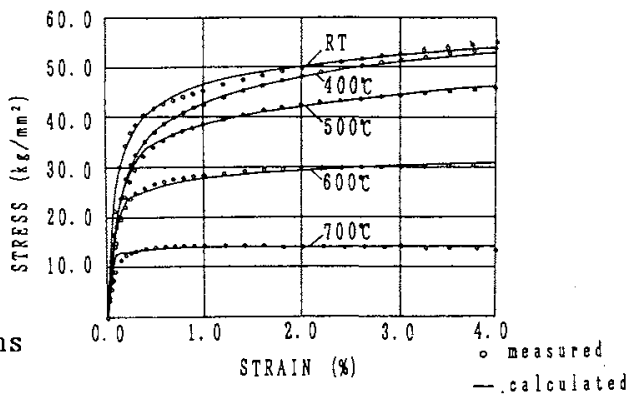

Pig. 2 Stress-Strain Curves of

Fire Resistance Steel(SM50A-NFR)

Loading System of bending compression test

Fig. 3 shows the loading system used in the experimental study. Loading system consists of 2 steel frames, a set of load bearing wall and floor made of reinforced concrete and 3 oil cylinders for which pressure and displacement are controlled by electric device. One cylinder is set horizontally for producing axial force and the others are set vertically for producing bending moment in specimen. For maintaining the loading directions in the central and vertical plane, 8 mechanical stoppers are fixed to the steel frames and connected to the transmitting beams, as shown in Fig. 3 .

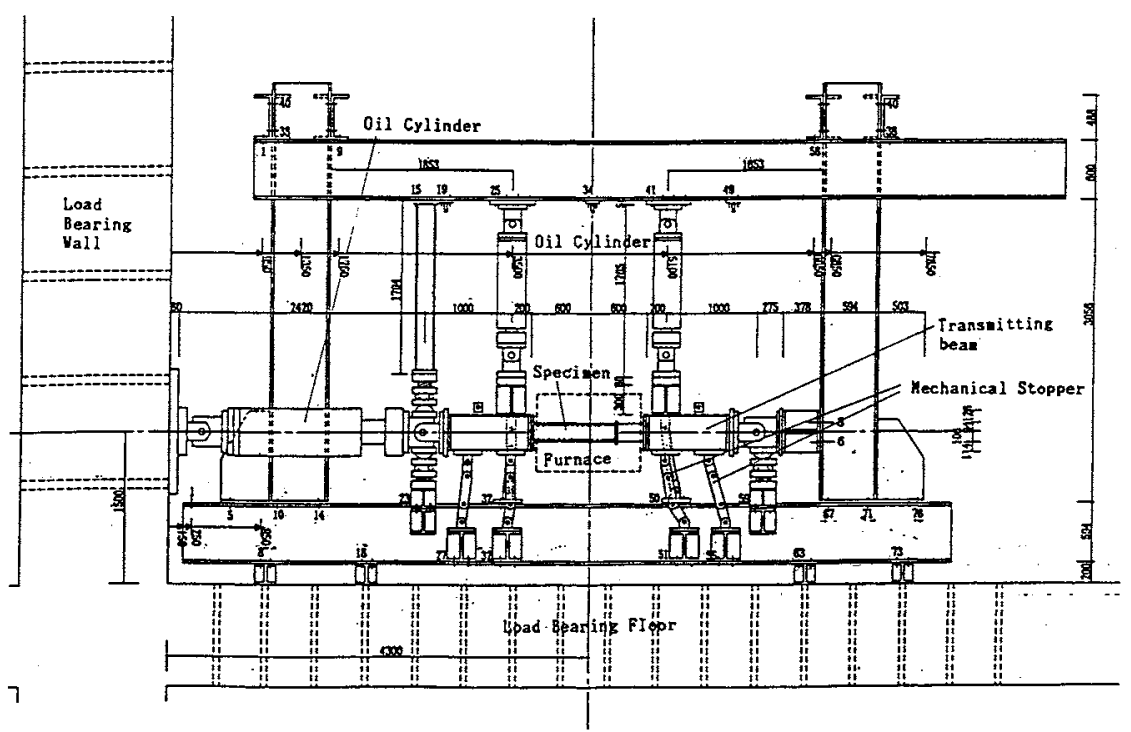

Fig. 3 Loading System in the bending compression test 
Heatig System of of bending compression test

Heating of specimens is caused by the box shaped electric furnace. The box has about $900 \mathrm{~mm}$ length, $550 \mathrm{~mm}$ width and $600 \mathrm{~mm}$ depth and has 3 windows on each side for measurements and observations. Heating panels are located on top, bottom and sides. Temperature of specimens is controlled by 5 transformers and measured with Cromel-Alumel thermocouples which are located at 20 points on the surface of a specimen and whose hot junctions are covered with stainless steel foil to avoid radiant heat from the heating panels.

Deformation Measurements of bending compression test

The deformations of the specimens are measured directly by a specially developed high temperature-deformation measuring device which is shaped like L character as shown in Fig. 4. The L character measuring bars are fixed to a diaphragm or an end-plate of a specimen with stainless bolts and maintain the same rotation as one of a diaphragil or an end-plate, respectively. With this device, the vertical relative deflections of a specimen are measured out of the furnace. The axial deformations are also measured out of the furnace by using stainless transmitting bars bolted on a specimen.

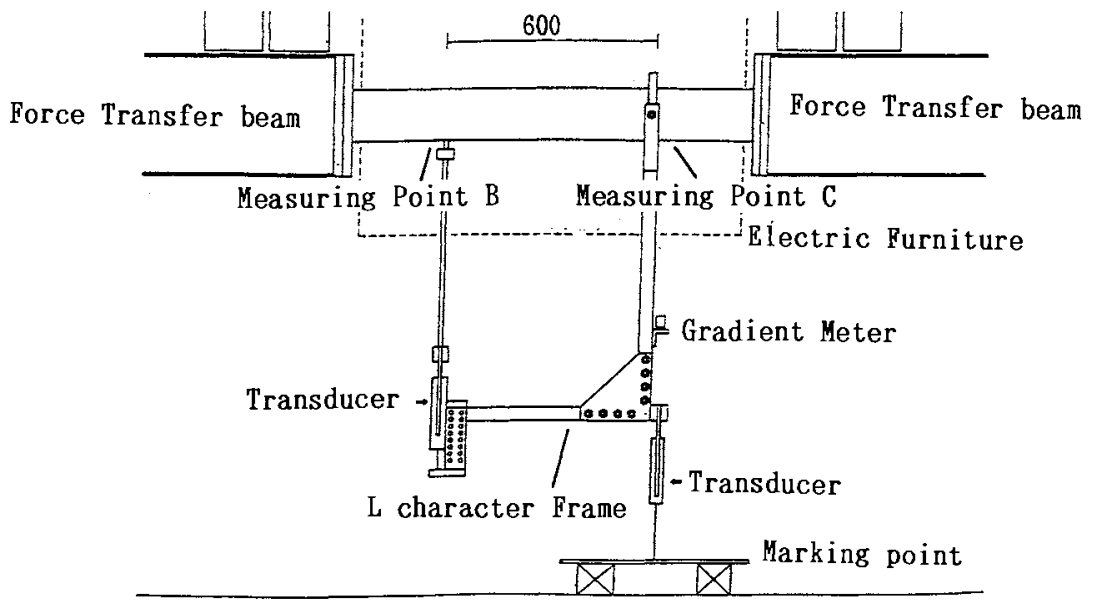

Fig. 4 Measuring Device

Experimental Procedure of bending compression test

The first step of the experiments is to heat a specimen without loading and end restraint and then to keep the prescribed temperature. After

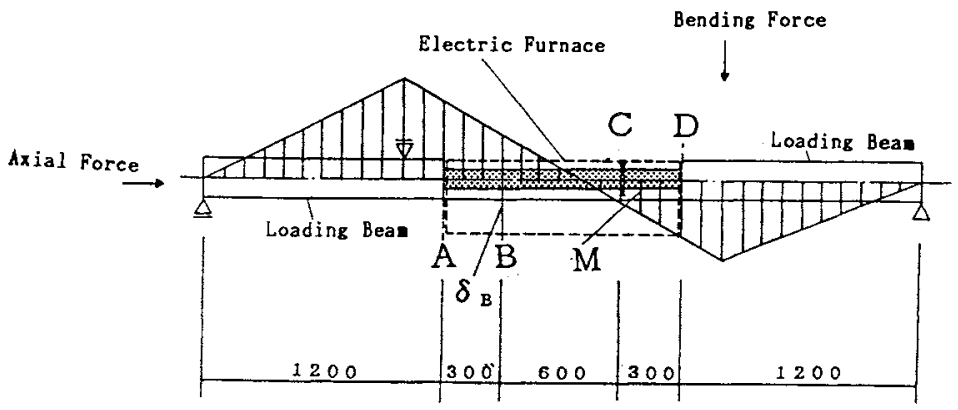

Fig. 5 Moment Distribution Emphasized 
steady-state temperature distribution of a specimen is attained, axial loading starts and bending loading is applied by the right side oil cylinder under controlled increasement of elongation and the lef $t$ side oil cylinder is maintained at initial position (see Fig. 3). Accordingly, bending moment distribution is obtained in a specimen and loading beams as shown in Fig. 5 . The measurement of loading forces, bending deflections and axial deformations are carried out at each loading step and loading is increased until the deflection of specimen reaches the limitations of the measuring device.

\section{EXPERIMENTAL RESULTS OF BENDING COMPRESSION TEST}

The results obtained from the experiments are shown in Fig. 6 Fig. 11. In these figures, the vertical axis gives the ratio of the measured bending moment $M$ at the position of a diaphragm to the plastic bending moment $\mathrm{Mp}$ at room temperature as shown in Table 2. The horizontal axis gives the ratio of the measured relative deformation $\delta_{\mathrm{B}}$ to $600 \mathrm{~mm}$ length which is the distance between the measuring point $B$ and a diaphragm in the specimen. Load-deformation curves of experimental results are shown as envelope curves which are non-dimensionalized. The bending moment ratio includes the effect of additional bending moment due to axial force, the $\mathrm{P}-\delta$ effect.

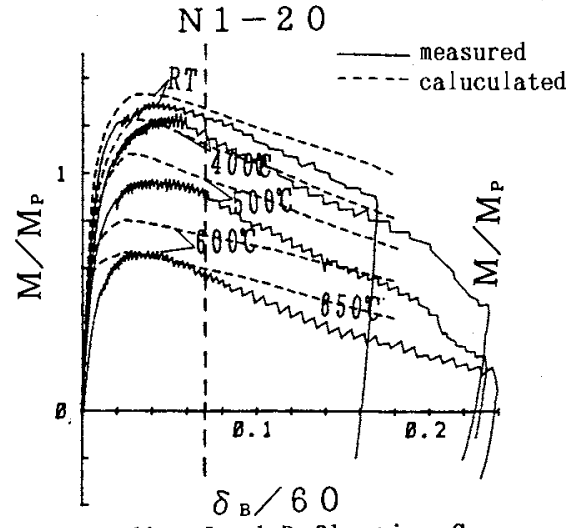

Fig. 6 Bending Load-Deflection Curves (Axial Force Ratio=0.15, width-Thickness $=20$ )

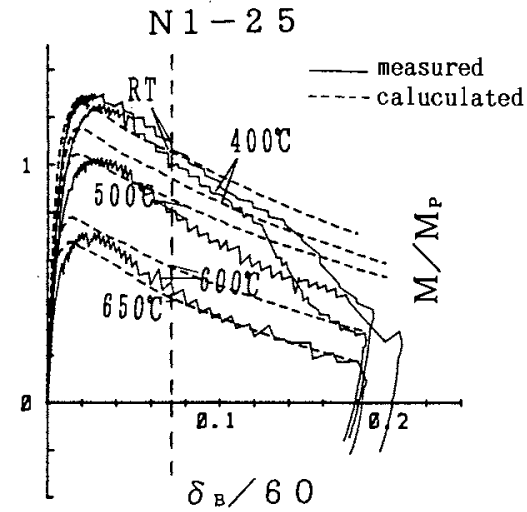

Fig. 8 Bending Load-Def lection Curves (Axial Force Ratio $=0.15$, Width-Thickness

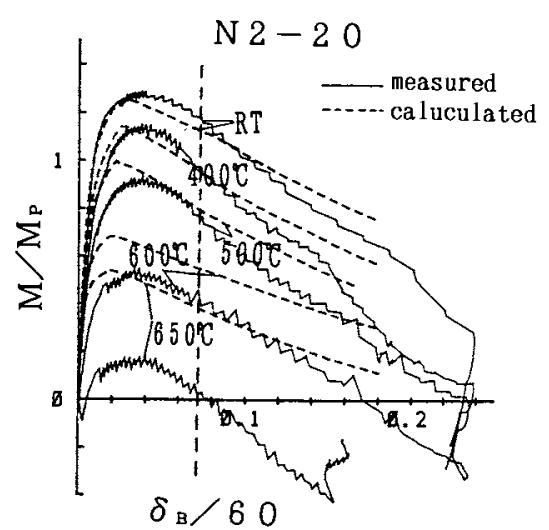

Fig. 7 Bending Load-Deflection Curves (Axial Force Ratio=0.30, Width-Thickness $=20$ )

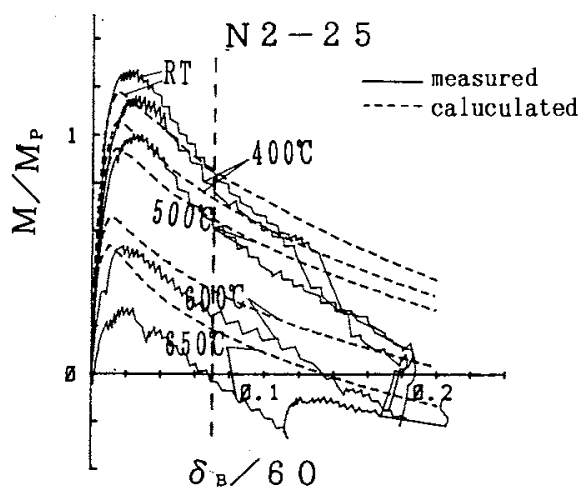

Fig. 9 Bending Load-Deflection Curves 25) (Axial Force Ratio=0.30, Width-Thickness=25) 


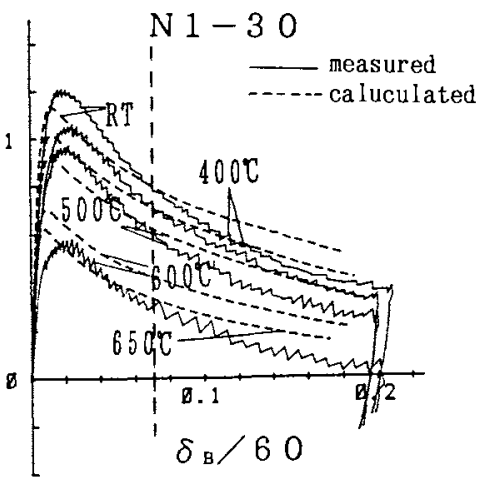

Fig. 10 Bending Load-Deflection Curves

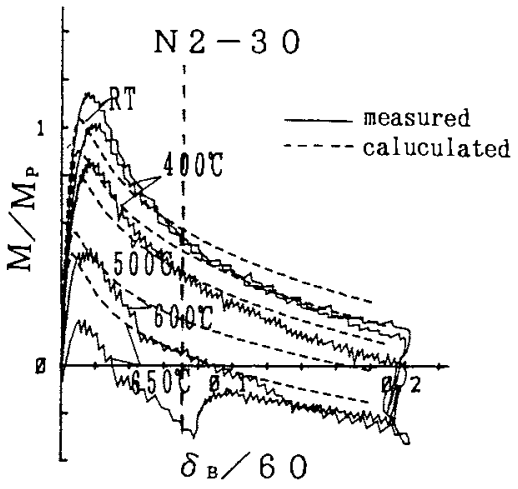

Fig. 11 Bending Load-Deflection Curves (Axial Force Ratio=0.30, Width-Thickness $=3$

Load-Deformation Curves of bending compression test

In room temperature tests, bending moment ratio indicates about 1.2 as the maximum value and gradually reduces according to deformation increment, accelerated by the local buckling of upper plates near a diaphragm as shown in Photo.1. In $400^{\circ} \mathrm{C}$ tests, bending stiffness starts to decrease from bending moment ratio $\fallingdotseq 0.8$ but bending strength continues to increase. In the specimen with width-thickness ratio 20 and 25 , the bending moment ratio reaches $1.1 \sim 1.2$ and in the specimen with width-thickness ratio 30 the bending moment ratio reaches about 1.0 as the maximum value. Local buckling occurred in the same position of a specimen as in room temperature tests. In $500^{\circ} \mathrm{C}$ tests, bending moment ratio shows the maximum value near 1.0 in all specimens. Local buckling also occurred in the same position of a specimen as in room temperature tests. In $600^{\circ} \mathrm{C}$ tests, bending moment ratio shows the maximum value between 0.5 and 0.6 for all specimens. Reduction of bending strength is clearly recognized. Local buckling also occurred in the same position as above.

The influence of axial load ratio is small for the bending strength but clear for reduction of bending moment after local buckling.

The influence of width-thickness ratio is also small for the bending strength and clear for reduction of bending moment after local buckling.

It is recommended that the 1 imit criterion with respect to the lateral deflection at the top of a column is $h / 30$ where $h$ means story height/5/. The maximum lateral deflection of outer column is h/50 in 48 computational analysis examples $/ 4 \%$. The required rotational angle of the top of a column exposed to

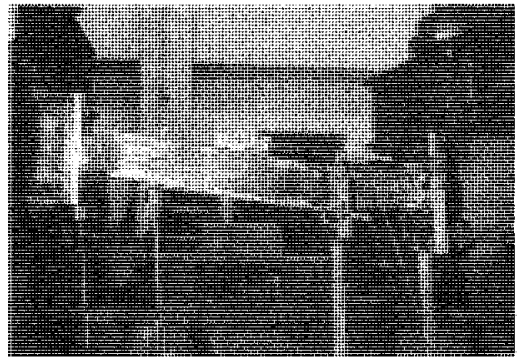

Photo. 1 Deformation of Specimen (T0-N1-25)

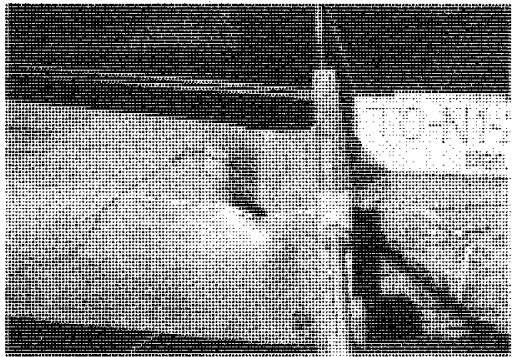

Photo. 2 Local Buckling of Specimen ( T0-N1-25) 
fire is the sum of the angle due to this lateral deflection and the rotational angle of the bottom of the upper story column . Therefore, it is sufficient that the criterion of rotational angle at the top of a column exposed to fire is $1 / 15$. This criterion is shown in Fig. 6 to 11 by a dashed line. It is clear that experimental results demonstrate sufficient bending deformation capacity.

\section{PURE COMPRESSION TEST}

The factors of pure compression test are almost as same as bending compression test. Therefore, same parameters of the experiments are set except of the axial force. Based on these parameters shown in Table 3 , the pure compression tests were carried out on 18 specimens.

Geometrical and mechanical properties of the steel specimens tested are as same as in the bending compression test shown in Table 2. The shapes and geometries of pure compression specimens are shown in Fig. 12. The length of specimens is $1,200 \mathrm{~mm}$ and the range of measuring portion where temperature distribution is rather uniform is $360 \mathrm{~mm} \sim 450 \mathrm{~mm}$ length between both diaphragm in a specimen as shown in Fig. 12.

Fig. 13 shows the loading system used in the pure compression test. Loading system consists of 2 steel beams and columns and 1 oil cylinder which is set horizontally for producing axial force. For maintaining the loading directions in the center axis, the inclined plates are set between the load cell and a specimen, as shown in Fig. 13.

Heating system and measurement of specimens are completely as same as the bending compression test.

The axial deformations are measured out of the furnace by using stainless transmitting bars bolted on a specimen.

In experimental procedure of pure compression test, the first step of the experiments is to control the direction of axial force which produce uniformal stress distribution on a section of specimen. The next step is to heat a specimen without loading to keep the prescribed temperature. After steady-state temperature distribution of a specimen is attained, axial loading starts. The measurement of loading forces and axial deformations are carried out at each loading step and loading is increased until the deflection of specimen reaches the limitations of the measuring device.

Table 3 Parameters of Pure Compression Test

\begin{tabular}{|c|c|c|c|c|c|c|c|}
\hline \multirow{2}{*}{ Specimen } & \multirow{2}{*}{$d / t$} & \multicolumn{5}{|c|}{ Testing Temperature $\left({ }^{\circ} \mathrm{C}\right)$} & \multirow{2}{*}{$\begin{array}{l}\text { Number } \\
\text { of } \\
\text { Specimen }\end{array}$} \\
\hline & & R. T. & 400 & 500 & 600 & 650 & \\
\hline$\square-135 \times 135 \times 4.5$ & 30 & 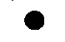 & 0 & 0 & 0 & 0 & 6 \\
\hline$\square-150 \times 150 \times 6$ & 25 & - & 0 & 0 & 0 & 0 & 6 \\
\hline$\square-120 \times 120 \times 6$ & 20 & ? & 0 & O & - & ? & 6 \\
\hline
\end{tabular}

$\mathrm{d} / \mathrm{t}$ : width thickness ratio

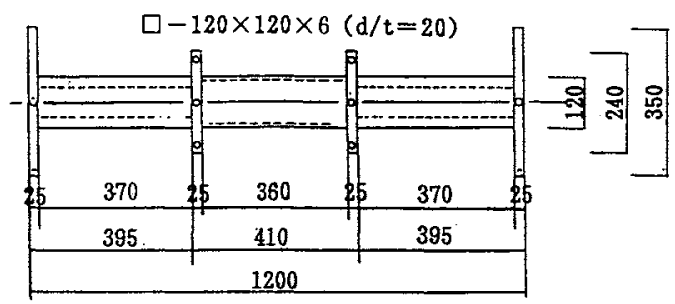

Fig. 12 Shape and Geometry of Specimens 


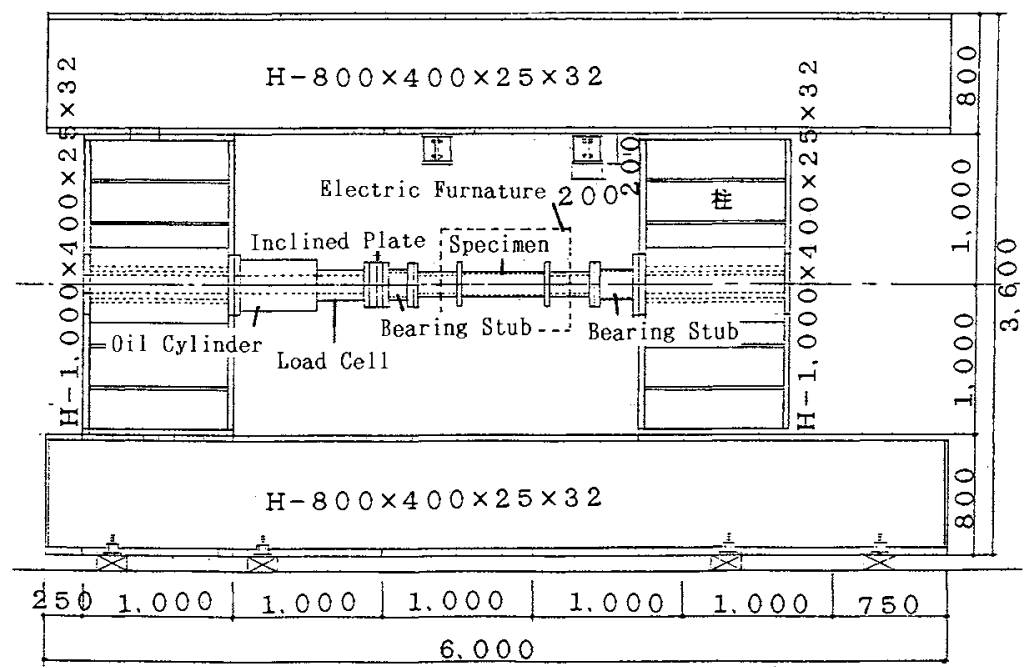

Fig. 13 Loading Systen in the pure compression test

The results obtained from the pure compression tests are shown in Fig. 14 Fig. 16. In these figures, the vertical axis gives the average compression stress at tested portion and the horizontal axis means the average strain between both diaphragms up to the maximum stress and after this stress means the value which is divided the deformation between both diaphragm by the specimen depth because the local buckling width is rough equal to the depth of a specimen. The maximum stresses appear at about $1 \%$ strain value and after this stress load bearing capacities decrease according to strain increasing at each temperature. $15 \%$ is the average ratio of the existent axial forces against the allowable strength in the building structure which are designed for seismic load and the additional axial force is generally very small as thermal stress[4]. It is clear that experimental results demonstrate sufficient compressive deformation capacity.

The stress-strain curves are obtained which contain the influence of local buckling. These curves are approximately predicted, using a next type equation. $\sigma=-\mathrm{a} \varepsilon^{\mathrm{b}}$ exp ( c $\left.\varepsilon\right)$

The comparison with the experimental values are shown with dashed lines in Fig. 14 Fig. 16.
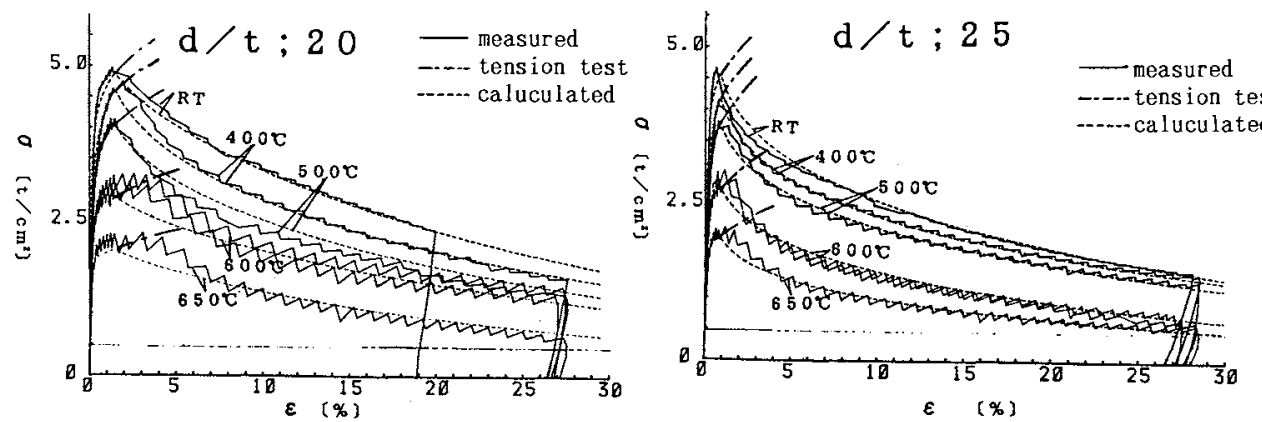

Fig. 14 Compressive Load-Deflection Curves Fig. 15 Compressive Load-Deflection Curve (Width-Thickness=20) (Width-Thickness $=25$ ) 


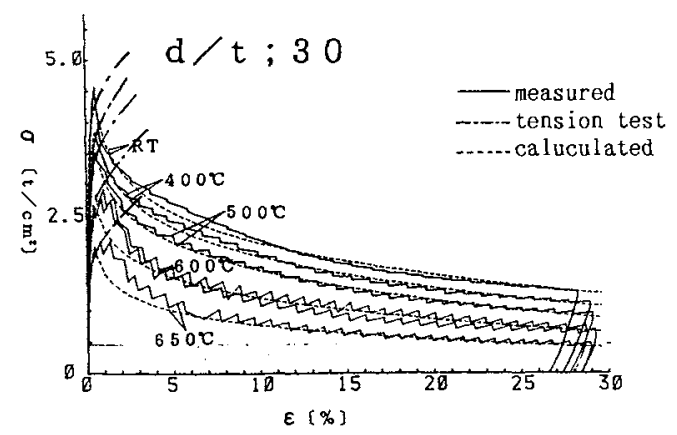

Fig. 16 Compressive Load-Deflection Curves

(Width-Thickness $=30$ )

\section{COMPARISON WITH CALCULATED RESULTS}

Computational analysis was carried out for the bending compression tests, using the stress-strain curves obtained by the pure compression tests and the program developed for structural steel frames exposed to compartment fire/4/. The non-dimensionalized relations, obtained by the computational analysis, between the bending moment at the position of diaphragm and the relative deformation $\delta_{\mathbf{B}}$ are shown in fig. $6 \sim$ Fig. 11 using dashed lines.

At room temperature and $400^{\circ} \mathrm{C}$, the calculated results generally agree with experimental results. At $500^{\circ} \mathrm{C}, 600^{\circ} \mathrm{C}$ and $650^{\circ} \mathrm{C}$, the calculated results are higher than experimental results, generally. If the numerical results are calculated based on stress-strain curves obtained only by tensile tests at elevated temperature as shown in Fig. 2, the calculated curves show continuous increasing which reflect the tensile stress-strain curves. But now, the calculated curves show primary increasing and secondary decreasing according to experimental results of the bending compression tests. This indicates availability of the compressive stress-strain curves for thermal stress and deformation analysis of a steel structure exposed to fire.

\section{CONCLUSIONS}

In Japan, high rise buildings are usually designed against seismic load. Axial force produced in columns of buildings are $15 \%$ of allowable axial force on an average at service time/4/. Under this condition, the following conclusions can be obtained from the experimental study.

The load bearing and the bending deformation capacity of the fire resistance steel tubular columns are sufficient for the section with width-thickness ratio $\mathrm{d} / \mathrm{t}=20,25$ and 30 between room temperature and $650^{\circ} \mathrm{C}$.

\section{ACKNOWLEDGMENT}

Execution of this experiment was supported by undergraduate and graduate students of Department of Architectural Engineering, Faculty of Engineering, Chiba University. The authors thank the persons engaged in the this experiments. 


\section{REFERENCES}

/1/ Article 107 in The Enforcement Ordinance of The Building Standard Act in Japan.

/2/ "Method of Fire Resistance Test for Structural Parts of Building", JIS A 1304-1975.

/3/ "Development of Design System for Building Fire Safety" projected by Building Research Institute, Ministry of Construction in Japan.

/4/ H. Sa i to, H. Uesug i, M. Yamaguch i, A. Kodaira," Thermal Stress and Deformation of Steel Structures of High Rise Buildings in Fire", FIRE SAFETY SCIENCEProceedings of the Second International Symposium, pp. 719-728, 1988.

/5/ ECCS-Technical Committee 3-Fire Safety of Steel Structures, "European Recommendation for the Fire Safety of Steel Structures",Elsevier Scientific Publishing Company, 1983. 